\title{
Teaching Models that Emerge from the Practice of Teachers at the Universidad Iberoamericana del Ecuador
}

\section{Derling José Mendoza Velazco}

\author{
PhD in Education, Research Teacher, \\ Instituto de investigaciones Científicas y Tecnológicas, \\ Universidad Iberoamericana del Ecuador (INCYT - UNIB.E)
}

\section{Jenniz La Madriz}

PhD in Educational Sciences, Research Teacher, Instituto de investigaciones Científicas y Tecnológicas, Universidad Iberoamericana del Ecuador (INCYT - UNIB.E)

Doi: 10.2478/mjss-2018-0117

\begin{abstract}
The didactics from its educational perspective, is located in the axis of reflection and theoretical operational projection, from the edge of interaction and communication, between the being of education and the dissimilar educational models. Therefore, the present study is based on generating a theoretical approach that arises from the practice of university professors. In this case, the Universidad Iberoamericana del Ecuador (UNIB.E) will be used as the research scenario. As a first objective, the didactic models that are frequent in the practice of university professors were analyzed. The second objective of the study was to interpret the relationship between the explicit theories, and those of common use, that university professors develop in their practice. To this end, the researchers carried out qualitative research based on the interpretative-hermeneutic paradigm, using a method of analysis and ethnographic study. Structured interviews and observations, both validated through expert judgement, were used as data collection techniques. Based on the information obtained, the importance of strengthening the didactic training of some teachers was detailed as important manifestations. Highlighting the conceptualization and effective application of the different models that arise in the andragogical practices of higher education.
\end{abstract}

Keywords: Educational models, Didactics, teaching practice

\section{Introduction}

At the university level, in the didactic planning environment, the teacher must always ask the following questions: How to plan an activity, how to operate or manage the teaching? from this aspect, didactics makes its vision as a discipline that allows the interpretation of teacher training, both in developed and underdeveloped countries, equally for public and private universities, in any educational modality or level; since didactics practice is conferred by rigorous and sophisticated methods and strategies, in addition to being assigned by its own theoretical and empirical objects.

However, at present, when it comes to analysing the traditional way of reasoning about didactics, the denial of the theoretical postulates of reference prevails in view, without which it suffers from a low scientific basis. In this way, a division is created between theory and practice: on the one hand, a dominant, hypertrophic and autonomous speculative pedagogy, and on the other, a didactic science as a minor science lacking in theory, forced to deal only with educational practice (Camilloni, et al, 2015). 
In this way, the teacher must acquire and put into practice a series of skills and competencies that accredit him/her as being able to unify what by training has been achieved or obtained with what really needs to be exercised at a given moment of teaching. In view of this, it is important to stress that one of the fundamental missions of university teacher training is to have continuous training and to develop further development in assessment and planning strategies so that they can then cultivate the same qualities and conditions for their students.

From the foregoing, there is an urgent need to contribute to the intellectual and objective growth of higher education teachers, who, throughout their professional careers, have dedicated themselves to the improvement and improvement of their areas, often leaving aside training in the didactic practice that must be carried out in order to achieve an effective and efficient teaching and learning process.

The perspective of didactic teaching must prevail in the daily work of each professor in the university sphere, since it is his duty to fuse his or her knowledge with the reality of the classroom and the institutional context, where each one begins to work and to guide his or her educational function, starting from action to reflection. Reflection that involves conscious decision making about the various ways in which academic content can be presented in order to develop the respective subjects or class moments.

Therefore, the researchers of the present study focused on generating a theoretical approach that conceptualizes andragogical practice from the perspective of UNIBE university professors. As it is common to listen to teachers, to identify with a current or model of teaching and learning. All with their corresponding didactic strategies, such as, for example, the development of critical (constructionist) thinking, leaving aside other models. Also from the traditional model, but in the real context of the classroom, they are wrong to put into practice didactic strategies from the traditional model, completely distancing the theory contained in teacher training from the contextual reality (teaching framework).

\subsection{Theory of experience}

Dewey (2009) was a great exponent of educational ideas; he defended the intention of unifying theory with practice. It's ideal was based on the fact that theoretical democracy is educational freedom. In other words, he focused on highlighting the importance of the relationship that exists between what establishes a curricular system and the reality faced by each of the subjects they learn. In addition to this, he points out that while democracy is advertised as an ideal system of subsistence. Then, it gives each being the opportunity to expose his ideas without any discussion, even more, when his thoughts can lead him to the domain of scientific disciplines.

$\mathrm{He}$ also investigated the proposal of a practical experimental institution where the author mentions, "The child goes to school to do things: to cook, to sew, to work wood and to make tools by means of simple acts of construction; and in this context and as a consequence of these acts the studies are articulated: reading, writing, calculation, etc. When children understood the usefulness of solving the problems of their practical activities, they were taught to read, since a reading can be read, but not understood, which makes them realize the importance of meaningful learning, that is, of the meaning that each person gives to the knowledge they acquire" (Cano, 2011).

As noted above, at university, students acquire basic knowledge. Each of them recognizes it as experiential. From these experiences, they will develop the content of the curriculum. According to Dewey, the student is more likely to be concerned about specific technical content, based on his or her previous experience and knowledge. That for trying to subjugate information that for them is totally alien to what they face every day. This mode of teaching can be carried out by the university professor. Through technical demonstration exercises and examples, all with the available elements and events taking place in a given period and space.

\subsection{The didactics}

Defining didactics and its role in the teaching and learning process dates back a long time; however, each one of them is inclined towards the study of the compendiums, which intervene in the educational work. From this perspective, the following author offers a definition referring to the 
concept that "Didactics is - is on its way to being - the theoretical-regulatory science that intentionally guides the process of optimizing teaching-learning, in a determined and interactive context, making possible the apprehension of culture in order to achieve the integral development of the student" (Sevillano 2005).

It can be said that didactics concentrates its attention on mediating, directing, guiding and training teachers, in order to consolidate the award of the different curricular contents, specific to each area of learning. In this way, the students/participants are provided with a pragmatic training, admitting their free expression but based on theoretical knowledge. This knowledge can be put into practice with responsibility and a certain degree of ease, depending on the skills and abilities of each individual.

\subsection{Teaching practice as a teaching task}

Ribot, Varguillas and Báez (2008), point out that "Didactics as a discipline in the field of education reaches Latin America, mainly from Central and Mediterranean Europe". The didactics is conceived as the discipline commissioned to study the practice, the ways of being, acting and above all teaching that teachers have with the aim of achieving a feasible and satisfactory learning. However, in the same way, this science of education is described as the attitude of those who act as students, apprentices, who externalize the reception of the information that for a moment is being presented, since this manifestation is the highest index of expression that allows us to know at what level the teaching is being firm and effective. However, in the field of higher education (research scenario), it is necessary to deliberate on a way of mediating and analyzing the existing context; with respect to the following author, he suggests, "The university teacher should be promoted as a pedagogue of his own practice and mediator of significant learning" (Díaz 2001).

The didactic praxis of higher education teaching staff has a decisive meaning in the training of students, since this action will determine the professional management of the future professionals who are being educated in the university. Therefore, whoever works as a university professor must know that his role is as Bruner (2001) would express it, in his theory of learning, of scaffolding; that is, as a connection point between what theory imposes, what is necessary to sustain ideas, and what really deserves to be taught in each discipline, the purpose of educational didactics, and bearing in mind that this researcher emphasized that there is no difference in learning at different stages of the study. Learning is the same from the level of basic education as in university, what should make a big difference is the way in which it is taught, that is, it is differentiated by the teacher with his methodology and didactic strategies.

When emphasis is placed on the way in which the teacher assumes the various methodologies for applying his or her teaching, the mode of educational thought that he or she puts into practice is immediately pointed out. To this end, the author points out that "The pedagogical thought would be composed of the knowledge that justifies pedagogical practice and has to do with the aims, the selection of contents, the didactic strategies, the assumptions about learning and the forms of evaluation of the subjects in specific contexts of formation; therefore, the pedagogical thought as a complex event can be made explicit from the curricular constructions that are assumed" (Cabezas 2011).

Thus, based on the theoretical structures that teachers have, they will be able to carry out the different didactic situations and, therefore, they will show an inclination towards certain didactic models, since they are the most appropriate ones in their opinion. All this pedagogical knowledge, which must master a subject with a teaching function, especially at university level. It must be merged with full mastery of certain skills, which confirm your ability to be a didactic promoter. Its function is oriented to the formation of citizens so that society requires their cultural, social and economic evolution, among other contexts.

\section{Research Methods}

In the methodological framework, the present research is based on qualitative research, described by "its philosophical conception, Platonic rationalism and postmodernity, and its practical application to phenomenology, since it seeks to understand social phenomena from the perspective 
of the individual: what interests us from this theoretical ascription is reality as it is lived by the individual" (Báez and Pérez 2014).

The study is coupled with the qualitative method, due to its broader sense of research that produces interpretive data, facilitated by key informant words or writings, as well as by the behavior observable by researchers. The interpretative paradigm is pointed out by authors as "the paradigm that obeys the philosophical conception from which it is nourished and that provides it with the foundations about the real and the possibilities of knowing it" (Yuni and Urbano 2005). In this sense, the researchers carried out data collection in the scenario where the subjects carry out their university teaching functions on a daily basis, with the intention of being able to observe directly and without the presence and influence of other elements that could distort the information provided.

The Universal Hispanic Dictionary (1961) indicates that the term hermeneutics comes from the Greek hermeneutic, which corresponds in Latin to interpretâri, that is to say the art of interpreting manuscripts or texts, especially sacred ones, to fix their true meaning. From another point of view, for the authors, hermeneutics is "therefore, the one who is dedicated to interpreting and unveiling the meaning of the messages, making their comprehension possible, avoiding any misunderstanding, favouring their adequate normative function and hermeneutics a discipline of interpretation" (Arráez, Calles and Moreno 2006).

Thus, the hermeneutic paradigm in the present investigation was used in view of the opportunity it offers to analyze the meanings that the informants gave to the different theoretical and practical constructs that emerged from the teaching praxis; where the implementation of different emotions, motivations and attitudes demonstrated by the subjects in study is evident.

Because of the adequacy of the qualitative research, the researchers conducted interviews with nine key informants to the maximum extent possible to obtain their views on the topics being addressed in order to achieve the objective of the study. The structured type of interview is used, where the authors stress that "the questions are fixed beforehand, in a certain order and contain a set of categories or options for the subject to choose from. It is rigidly applied to all study subjects. It has the advantage of systematization, which facilitates classification and analysis, as well as high objectivity and reliability" (Díaz et al. 2013).

Thus, by using the interview with the nine professors who participated in the research. Each of them responded in an entertaining and measured way to each topic, using the knowledge they possessed according to their area of academic training. Thus, once the required information had been collected, the authors proceeded to propose their own interpretations, taking into account the opinions obtained.

In conjunction with the interview, the authors applied observation as a technique to collect information and then analyze it, where they responded to the emerging concerns of this research. The authors based themselves on the authors who define observation as "a research methodology in which the observer elaborates descriptions of the actions, discourses and daily life of a social group. It captures and records the discourse of the expected actors of their own meanings and significance" (Yuni and Urbano 2005). In this regard, the researchers detailed the educational action of university professors in a register of observed data, as well as the conduct of a didactic day for the professors.

Reliability in research, according to the author, "is that which is stable, secure, consistent, equal to itself at different times and predictable for the future. Reliability has two sides, one external and the other internal: there is external reliability when independent researchers, when studying a reality at different times or situations, arrive at the same results; there is internal reliability when several observers, when studying the same reality, agree in their conclusions (Martínez 2004).

In this regard, the present study is reliable, since the researchers applied the structured interview and the same technique on three different occasions, obtaining similar results, that is, the answers of the key informants coincided with the object of the research. To achieve this principle, the researchers' triangulation was applied, where the authors state "data analysis can be carried out independently for each of the researchers and then compared using consensus to agree on the findings" (Okuda and Gómez 2005).

As for validity, the expert judgment was used, where three specialists in the area inspected the questions to be executed and formulated their opinions on the different adjustments that should be 
made in order to guarantee the obtaining of information that corresponds to the object of investigation.

For the analysis of the information collected, the researchers followed the indications of the above-mentioned authors where qualitative data analysis involves, on the one hand, conceptual tasks, in which the researcher generates coding categories, relationships and even theories after reading, reflecting, inducing, etc. as well as mechanical tasks, in which the researcher stores, organizes and retrieves data through coding categories. The latter can be carried out effectively with the help of computer resources" (Osses, Sánchez and Ibañez 2006).

When the cited authors point out that it must be approached in a systematic way, oriented to generate constructs and establish relations between them, constituting this methodology, in a way to arrive in a coherent way to the theoretical approach. As its term indicates, the term systematization refers to a system, that is, an interconnected group of elements treated in a holistic manner. To achieve the theorization, the researchers applied the qualitative analysis software Atlas.ti, version 8. We applied the contrast of the opinion of the different informants, (specialists in different areas of learning), by uniting the written observations and theoretical positions proposed, with the theoretical construction and other data consulted. Thus, to obtain the conceptual support of the thematic units, main categories and emerging categories, through the authors' own opinion, based on their analytical criteria.

\section{Result of the analysis}

After the data obtained were contracted, the categories were coded using the symbols $\pi$ (pi), $\alpha$ (alpha), $\varepsilon$ (epsilon), $\varsigma$ (sigma) and $\varphi$ (phi) for better performance in their interpretative analysis, and the triangulation process was subsequently carried out. A graphical representation of structural networks was then made where the most prominent indicators were extracted from each block of opinions and defined according to the textual framework referred to in each particular case. Finally, the information obtained through the observation notes is analyzed, thus contrasting what the subjects express with what is actually done by them, where the following five categories emerge.

\subsection{Category $\pi$ (pi). Characterization of Teaching Practice}

Teaching practice is represented as a category as it is an essential characteristic in the educational society of UNIB.E, based on the demonstration that the university professional has on the mastery of the contents and information he transmits to the students. Hence, there is no unified style, but each teacher adopts it depending on the needs of the teaching practice. However, the university teacher under study must foresee that every community has the need to preserve certain knowledge and values, which it considers essential in order to maintain its cultural and research identity. This does not imply, for Bertoni (2009), "staying in the past" but opening up to the future by exploring the cognitive, ethical and creative possibilities of the human being.

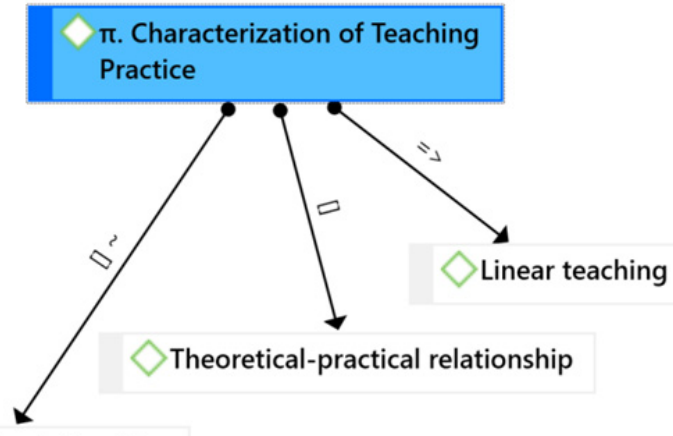

Contextual relationships

Figure 1: Category п (pi). Characterization of Teaching Practice 
Figure 1 shows the structural network, which represents the category $\pi$, that is, the characterization of teaching practice; the subcategory is the contextual relationship, where the teachers expressed the importance of relating the didactic content with the reality that each student lives, so that learning is authentic and real for the students.

In correspondence with the theory - practice subcategory, the data reflected great importance to the contextual model, as teachers sought to relate as much as possible the theory that includes their area with the practice that corresponds to it. Responding to the constructivist paradigm of educational practice at UNIBE, the teachers shared their opinions with the students in order to progress cognitively and personally. The researchers found that both teachers and students value the ability to engage in new opinions.

\subsection{Category a (alpha). Didactic Models Known and Applied by Teachers}

To describe the category $\alpha$, established as teaching models known and applied by teachers, emphasis should be placed on the term "model" in teaching. Conceptualized by the authors as, "a stereotype of a possible alternative to teaching-learning. Like any other, didactic models are an interpretation of reality, which are only valid in a given field of application, but whose interpretation is often inaccurate, outside the limits of usefulness, that is, they have a range of validity" (Chrobak and Benegas 2006).

Based on the above, different teaching models can be analysed, which teachers know and apply in their practices. As can be seen in the structural network in figure 2, providing a great deal of information on the work of each of the teachers under study. Through the description, understanding and interpretation of the true purpose of stimulating learning, of a relevant type for university teachers, through didactic techniques in their educational practice.



Figure 2: Category a (alpha). Didactic Models Known and Applied by Teachers

In addition to a wide variety of teaching models and strategies to be used in the classroom, this may be one of the main reasons for opinions. Teachers may not even be able to easily define their methodological tendencies in the development of their activities. The traditional subcategory stands out, where it represents the behaviorist theory, which attributes greater importance in the participation and execution of the teacher. In the didactic environment, it is evident with the application of objective evaluations, expositions, quantitative instruments and objectives.

The hermeneutic subcategory emerges due to the interrelationship of practical analysis with written productions, as well as its relationship with the reality of the readers. Constructivist strategies as a subcategory were highlighted by the students' empowerment in the construction of knowledge, with the figure of the teacher as mediator and guide, applying mental, conceptual, schematic, analytical and structural maps.

The spontaneous model was represented in the search for voluntary participation, accessible to students, strengthening their areas of close development. Then, as a didactic model, the 
technological one, which focused on the support of the teaching action, through science as a discipline that frames the educational task. Finally, as a subcategory, the contextual didactic model, which focuses on analyzing each of the topics developed in the classes, relating them to the reality of the students, starting from the experiences of each one, in order to obtain significant learning.

\subsection{Category $\varepsilon$ (epsilon). Traditional model as a measure of student knowledge}

The category $\varepsilon$, as a traditional model for the teaching process. Researchers characterized it with absolute authoritarianism, where the teacher exercised his opinion without taking into account the students. According to Piaget (1999), "proven traditional ways of teaching are effective within a social group". This didactic position, distinguished by university teachers, cannot be considered wrong, since, if teaching styles are described, they vary depending on the reality that each teacher lives in a specific moment.

In the opinion of the informants of the study, they stated that they did not have control over the content of the traditional model; this teaching model is used taking into consideration the characteristics of each area of knowledge. His methodological skills, among the most relevant of which are presentations, productions, evaluation, objective tests and practical experiments. They allow for the most precise approach to knowledge on the part of students, established in two contexts of great importance. As can be seen in Figure 3, where the development of activities and quantitative evaluation is considered by the reporting teachers to be truthful and effective.

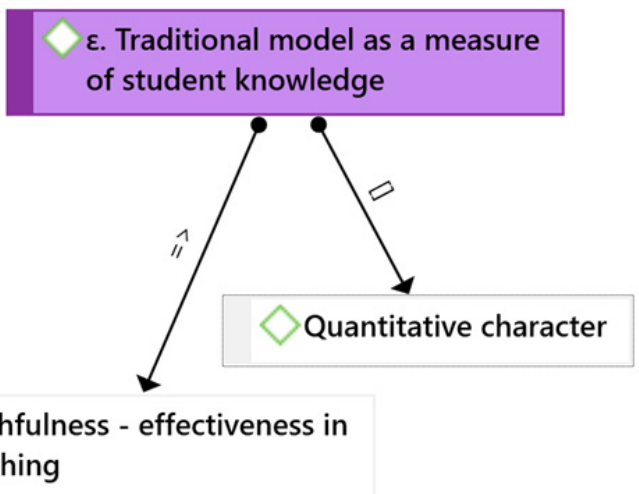

Figure 3: Category $\varepsilon$ (epsilon). Traditional model as a measure of student knowledge.

Requessen (2009), states that the traditional didactic model "aims to train students by making them aware of the fundamental information of current culture. The contents are conceived from a rather encyclopaedic perspective and with a cumulative and fragmentative character, that is to say, the knowledge corresponding to one subject plus the knowledge corresponding to another, and so on". According to the author, for researchers this model focuses their attention on the achievement of pre-established content based on standardized theories and methodologies, where the principle of individuality of students is not usually taken into account. For teachers, all students are generalized in their teaching style, putting into practice their ability and execution of didactic strategies that allowed for inclusion.

As an emerging subcategory the quantitative character is evidenced by the frequent execution of objective tests where the student captures the content learned. Likewise, it is considered a model of truthfulness - effectiveness in teaching, since it provides greater certainty in the teaching-learning process since it focuses on the search for solutions to the objectives presented by the university professor as an expert in the area or subject. 


\subsection{Category s (sigma). Adaptation of the contents to the contextual reality}

The key informants expressed in their testimonies the need to relate the contents of the analytical programmes to the needs and interests of the students. From this point of view, it is the task of each of the teachers to operate different strategies for the promotion of valid and satisfactory learning, for the demands of their own educational group. Applying traditional and technological resources, thus promoting an active link. Among the provisions of the programs with the indigenous experiences and learning of the students (Figure 4).

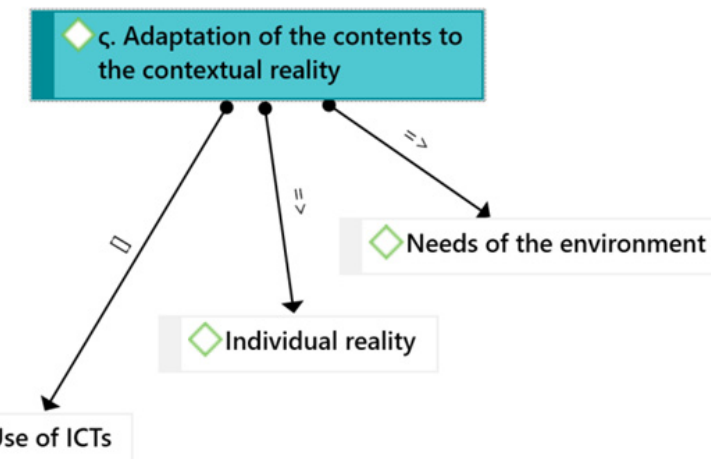

Figure 4: Category $\varsigma$ (sigma). Adaptation of the contents to the contextual reality

As for the adaptability, of the andragogical practice of UNIB.E university teachers. The teachers indicated that they would try to adapt and adapt the programmatic contents to the contextual reality. Considering that many changes are affecting the need for change in the teaching profession. From this perspective, it should be borne in mind that the contemporary university is directly linked to the vertiginous changes that are occurring in Ecuadorian society. In this regard, the author states that "universities and institutes of higher education in Latin America are faced with the need to renew themselves and to become the most essential elements of their educational function, not only because of historical needs, but also because of the nature of the changes that have already taken place and which are rapidly enveloping humanity" (Tamez 2003).

From this perspective, it is vitally important to redimension the continuous training of teachers in line with the changes demanded by today's society. To achieve this admission, teachers must be able to consider the needs of each of their students (physical, emotional, professional, personal) in order to articulate what has been given through the different curricular programs with what is significant for each of the participants.

The current era is characterized by the constant introduction of technology in the educational field. Thus, the subcategory established as ICT use emerges. Due to its frequent use, as a didactic resource and for the search of information through the networks. The individual reality subcategory reflects that each student is perceived and treated as a unique being, with different learning rhythms. Finally, the subcategory needs of the environment emerges because each of the students has a context with characteristics that make them particular. Therefore, teachers must acquire the tools to face these realities.

\subsection{Category $\varphi$ (phi). Teacher's skills in the didactic act}

For the author, competence "is a construct, the result of a relevant combination of several resources: A competent person is a person who knows how to act in a relevant way in a particular context, choosing and mobilizing a double set of resources: personal resources (knowledge, knowhow, qualities, culture, emotional resources...) and network resources (databases, documentary networks, networks of specialized expertise, etc.)" (Le Boterf 2001). 
The cited author expresses the combination of resources that a person possesses, in relation to the interviewees who glimpse the function of the current teacher as the person in charge of guiding his students towards the achievement of the satisfaction of their basic needs and progressively moving towards the consolidation of the citizen required by contemporary society.

In relation to the testimonies, it is during the process of teacher training that the strongest platform is built to appropriate a didactic knowledge, which will allow them to demonstrate or show their didactic skills.

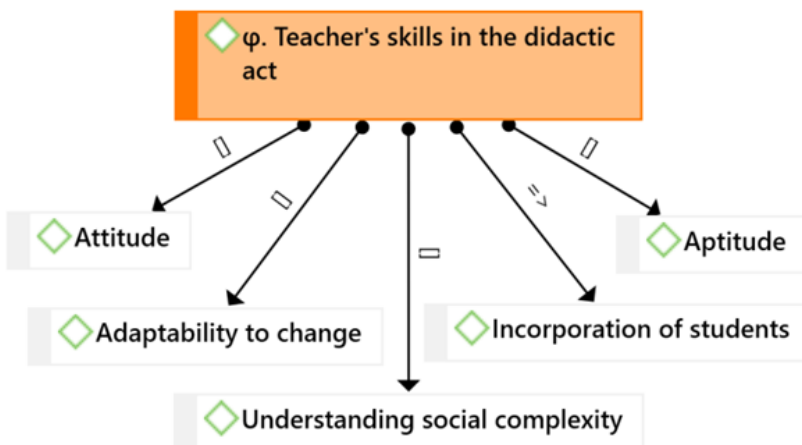

Figure 5: Category $\varphi$ (phi). Teacher's skills in the didactic act

Among the emerging subcategories found in the structural network of Figure 4, the incorporation of students portrays, who are protagonists in the educational process, therefore, their opinions are considered to enrich the didactic act. Adaptability to change is highlighted by the nature of the teacher as a social promoter, i.e. every university teacher must have an open mind to the incorporation of the social changes that underlie his or her teaching practice.

Understanding social complexity, as the next subcategory, represents the countless number of subjects in the social environment, where teachers have multiple ways of proceeding for an intercultural sense, where the teacher takes into consideration in his or her educational practice. The researchers were able to highlight the aptitude of the professors. Where the different abilities of UNIB.E teachers to resolve the different situations that may arise at any given time are manifested. As well as the attitude that represents the way of facing each situation, permanently adjusting to the norm and common sense, without allowing anything to interfere with the true essence of their teaching and guiding role.

\subsection{Theoretical approximation}

After analysing the categories emerging from the research, which resulted from the application of the interviews and observation to UNIBE university lecturers. Reference is made to a conceptualization of the didactic model as demonstrated by the key informants. Where the authors of the study note that most of them define it as a guide or pattern to follow, which previously has a series of structured steps, to reach the consolidation of a proposed goal.

From there, it should be borne in mind that the definition of the didactic model constitutes a fundamental instrument to approach the teaching and learning process. It is the way, although not strict, that guides and induces the choice of didactic strategies, teaching methods that must be adapted and applied according to the context and situation that is becoming evident at a given moment.

As mentioned throughout the research, when trying to limit the conceptualization and types of didactic models existing in the university under study, teachers may mention the different aspects they are familiar with. However, in the theoretical body the different models were reflected, which different authors postulate according to their studies. It was found that once again, although lacking technical knowledge, these subjects carry out multiple activities specific to each of them. 
Mentioning the traditional model, also handled as a behaviorist. Considering this, according to their knowledge as the best way to lead students towards the achievement of meaningful learning.

This position invites us to meditate and analyze the reality of the classroom in the university context, in the search to overcome an attitude of informing professors for that of committed formators, who assume the integral development of the new teachers. Didactics, therefore, can be configured as a study of teaching practice. This study, which critically reflects and constructs its conceptual apparatus according to its plurality of research methods, affirmations and values of truths, must be systematically compared with each other, not only on the level of internal coherence, but also, and above all, on that of external validity and reliability.

In all of the above, it is possible to structure a theoretical approach that defines the didactic model based on the emerging categories. As a science of autonomous education, where its task is not so much to ensure integrality and values to the education of the person. Rather, as a practical style, to facilitate the transfer of knowledge and social life model from an issuer (a teacher, a university) to a recipient (a student in education).

\section{References}

Arráez, Morella; Calles, Josefina; Moreno de Tovar, Liuval (2006). La Hermenéutica: una actividad interpretativa. Sapiens. Revista Universitaria de Investigación, vol. 7, núm. 2, diciembre, 2006, pp. 171181. Universidad Pedagógica Experimental Libertador. Caracas, Venezuela.

Báez J. y Pérez de Tudela (2014). El método cualitativo de investigación desde la perspectiva de marketing: el caso de las universidades públicas de Madrid. Tesis Doctoral. Universidad Complutense de Madrid Facultad de Ciencias Económicas y Empresariales. Available in: http://eprints.ucm.es/29615/1/T35974.pdf

Bruner, J. (2001). El proceso mental en el Aprendizaje (2a ed.). Spain.

Bertoni, M (2009). Acerca De Las Competencias Profesionales. Universidad Pedagógica Experimental Libertador. Mérida, Venezuela.

Cabezas, J. (2011). Consideraciones preliminares requeridas para ejercer la enseñanza. Universidad Valle del Momboy. Valera, Venezuela.

Camilloni, A; Davini, M; Edelstein, G; Litwin, E; Souto, M; y Barco, S. (2015). Corrientes Didácticas Contemporáneas. Spain.

Cano, C. (2011). John Dewey Y Su Pedagogía De La Acción. Available in: http://scarball.awardspace.com/documentos/trabajos-de-filosofia/Jonh-Dewey.pdf

Chrobak, R, Benegas M. (2006). Mapas conceptuales y modelos didácticos de profesores de química. Universidad Nacional del Comahue, Argentina.

Dewey, J. (2009). Democracia y Educación. United States.

Díaz L; Torruco U; Martínez M; Varela M. (2013). La entrevista, recurso flexible y dinámico. Investigación en Educación Médica, vol. 2, núm. 7, julio-septiembre, 2013, pp. 162-167. Universidad Nacional Autónoma de México. Distrito Federal, México.

Díaz, D (2001). La didáctica universitaria: una alternativa para transformar la enseñanza. Acción pedagógica. Venezuela

Le Boterf, G. (2001). Ingeniería de las competencias. Gestión 2000, Barcelona.

Jackson W. (1961). Diccionario Hispánico Universal. Distrito Federal, México.

Martínez, M. (2004). La investigación cualitativa etnográfica en educación. México

Okuda, M. y Gómez, C. (2005). Métodos en investigación cualitativa: Triangulación. Magazine colombian de psychiatry, 34(1), 118-124. Colombia.

Osses S., Sánchez I, Ibañez F. (2006). Investigación cualitativa en educación. Hacia la generación de teoría a través del proceso analítico. Studios Pedagogics XXXII, No1, 119-133. Available in: https://scielo.conicyt.cl/scielo.php?script=sci_arttext\&pid=S0718-07052006000100007

Piaget, J. (1999). De la pedagogía. Argentina. Paidós.

Ribot de Villegas, S; Varguillas C; Báez, E (2008). Modelo didáctico del profesor universitario: una experiencia pedagógica. Venezuela

Requessen, E. (2009). Una revisión de los modelos didácticos y su relevancia en la enseñanza de la ecología. Revista argentina de ciencias y humanidades. Available in: www.sai.com.ar/metodologia/rahycs /rahycs_v7_n1_03.htm

Sevillano, M. (2005). La Didáctica En EI Siglo XXI. Madrid. Spain.

Yuni, J, Urbano, C. (2005). Mapas y herramientas para conocer la escuela. Investigación etnográfica. Investigación acción. Metodologías cualitativas. Argentina. 